\title{
Use of B95a Cells for Isolation of Canine Distemper Virus from Clinical Cases
}

Chieko KAI, Fumiko OCHIKUBO ${ }^{1)}$, Masatsugu OKITA, Tetsuo IINUMA ${ }^{2)}$, Takeshi MIKAMI, Fumio KOBUNE ${ }^{3)}$, and Kazuya YAMANOUCHI ${ }^{4)}$

Department of Veterinary Microbiology, Faculty of Agriculture, The University of Tokyo, Tokyo 113, ${ }^{1)}$ Tsukuba Primate Center, Ibaraki 305, ${ }^{2)}$ Keyakigaoka Animal Hospital, Kanagawa 225, ${ }^{3)}$ National Institute of Health, Tokyo 190-12, ${ }^{4)}$ Nippon Institute for Biological Science, Tokyo 198, Japan

(Received 18 June 1993/Accepted 3 August 1993)

ABSTRACT. Canine distemper virus (CDV) was readily isolated at high rate with marked cytopathic effect (CPE) in B95a cells, a marmoset lymphoid cell line, from the peripheral blood leukocytes, cerebrospinal fluid cells and brain of dogs. Difference in type of $\mathrm{CPE}$, i.e. syncytium type and round-cell one, among the virus isolates indicate the presence of heterogeneity of virus populations in prevalent CDV. Thus, this cell system is expected to be useful for ecological studies on CDV in the field.-KEY worDs: B95a cell, canine distemper virus, virus isolation.

Canine distemper is the most popular virus infection in dogs caused by canine distemper virus (CDV) which belongs to the genus Morbillivirus, family Paramyxoviridae. Dogs can be protected from the infection by live attenuated vaccine. Nevertheless, increasing incidences of canine distemper in pups in suburb areas and in urban kennel shops have recently been noticed in spite of vaccination (to be published). Apparent failure in vaccination is considered to be due to the presence of maternal antibody which interferes with vaccine virus. As another possibility, antigenic changes in currently prevalent CDV against which the current vaccine does not give complete protection are also speculated. Similar possibilities have now been discussed for measles virus which belongs to the same Morbillivirus genus and closely related with $\mathrm{CDV}[4,14]$.

Characteristics of prevailing CDV in the field, however, have not been investigated due to difficulties in isolation of wild CDV from the field materials. Vero cells have been widely used for the isolation of CDV as well as of measles virus [13], but this system is not practical since several passages in the cells are required for virus isolation. Canine lung macrophage cultures have been employed for the isolation of CDV without losing its virulence $[1,2]$, but the cells are often contaminated with bacteria. Virulent CDV replicates well in mitogenstimulated canine or ferret lymphocytes. However, cytopathic effect (CPE) is not produced in these cells, so that the cultures have to be co-cultured with susceptible cells such as Vero cells after confirming the presence of virus antigens by immunofluorescent technique [1]. With such primary cells, their preparation as well as possibility of contamination with other canine viruses make them not practical. Considering these drawbacks in the use of primary cells, we attempted to use B95a cells of marmoset $B$ lymphoid cell line which have been reported to be highly susceptible host for the isolation of wild measles virus from patient's materials [8] and of lapinized rinderpest virus from the rabbit tissues [9].

In the present study, we succeeded in the isolation of CDV at high rate from clinical samples by using B95a cells. Some biological characteristics of CDV isolates were compared with those of a laboratory strain of CDV.
Six dogs clinically diagnosed as canine distemper, five from an outbreak in a kennel and another from a different house, were sent to our laboratory animal facility and observed for clinical signs. These dogs showed respiratory signs followed by neurological signs of disease. Tissue samples were collected from dogs at the time of death or after euthanasia, fixed in $10 \%$ formalin, and embedded in paraffin. Tissue sections were examined by hematoxylineosin (HE) staining for histopathological lesions. Some sections were subjected to luxol fast blue (LFB) staining. Distribution of virus antigens and astrocytes were examined by avidine biotin complex (ABC) method using monoclonal antibody against $\mathrm{N}$ protein of the FXNO strain of CDV [6] and rabbit serum against glial fibrillary acidic protein (GFAP).

Virus isolation was attempted on the peripheral blood leukocytes (PBL) separated on Ficoll Hypaque solution, the cerebrospinal fluid (CSF) cells, and $10 \%$ extract of the spleen, lung and brain. These samples were co-cultured with B95a cells, and the PBL were with Vero cells. The cultures were microscopically examined for the appearance of $\mathrm{CPE}$ and for virus antigens by immunofluorescent technique using the monoclonal antibody against $\mathrm{N}$ protein of CDV.

Clinical courses and virus isolation in B95a cells are summarized in Table 1. Dog Nos. 1-5 with ages from 1 to 5 months were from the same kennel, and all of them had received live attenuated distemper vaccine. All of them showed respiratory signs first followed by neurological signs. None of them had virus neutralizing antibody either in the serum or CSF. The appearance of CPE was recognized in 5 days in the B95a cells co-cultured with PBL and CSF cells, and in 6 days with the brain of dog No. 4 which showed chronic course with respiratory signs and euthanized after the appearance of neurological signs. The CPE was also noticed in 4 days in the B95a cells co-cultured with the PBL, brain and spleen of dog No. 5 which showed acute clinical course. These fused type CPE enlarged after a passage. In those co-cultured with the brain and PBL of Dog No. 6, however, the CPE had not been noticed in usual microscopy. The round-cell type CPE was demonstrated by indirect immunofluorescent technique after the second passage. In contrast to dog 
Table 1. Clinical courses and virus isolation in B95a cells

\begin{tabular}{|c|c|c|c|c|c|c|c|c|c|c|c|}
\hline \multirow[b]{2}{*}{ Dog } & \multirow[b]{2}{*}{ Age } & \multirow[b]{2}{*}{ Vaccination } & \multicolumn{2}{|c|}{ Clinical course } & \multicolumn{2}{|c|}{ VN antibody } & \multicolumn{5}{|c|}{ Virus isolation at autopsy } \\
\hline & & & $\begin{array}{l}\text { Neurological signs } \\
\text { (days of duration) }\end{array}$ & $\begin{array}{l}\text { Outcome (days after } \\
\text { respiratory signs onset) }\end{array}$ & Serum & CSF & Brain & CSF & Spleen & PBL & Lung \\
\hline 1 & $5 \mathrm{M}^{*}$ & Yes & 5 & Died (17) & - & - & - & $\mathrm{ND}^{* *}$ & - & ND & - \\
\hline 2 & $3 \mathrm{M}$ & Yes & 2 & Sacrificed (21) & - & - & - & - & - & ND & ND \\
\hline 3 & $4 \mathrm{M}$ & Yes & 14 & Sacrificed (28) & - & - & - & - & - & - & - \\
\hline 4 & $5 \mathrm{M}$ & Yes & 3 & Sacrificed (70) & - & - & + & + & ND & $t^{* * * *}$ & ND \\
\hline 5 & $1 \mathrm{M}$ & Yes & 2 & Sacrificed (7) & - & - & + & - & + & + & - \\
\hline 6 & $15 \mathrm{Y}$ & No & 35 & Sacrificed (35) & 40 & - & + & - & ND & + & ND \\
\hline
\end{tabular}

*M: Months, Y: Years. ${ }^{* *}$ ND: Not done. ${ }^{* * *}$ Virus was also isolated at 10 and 20 days before euthanasia.
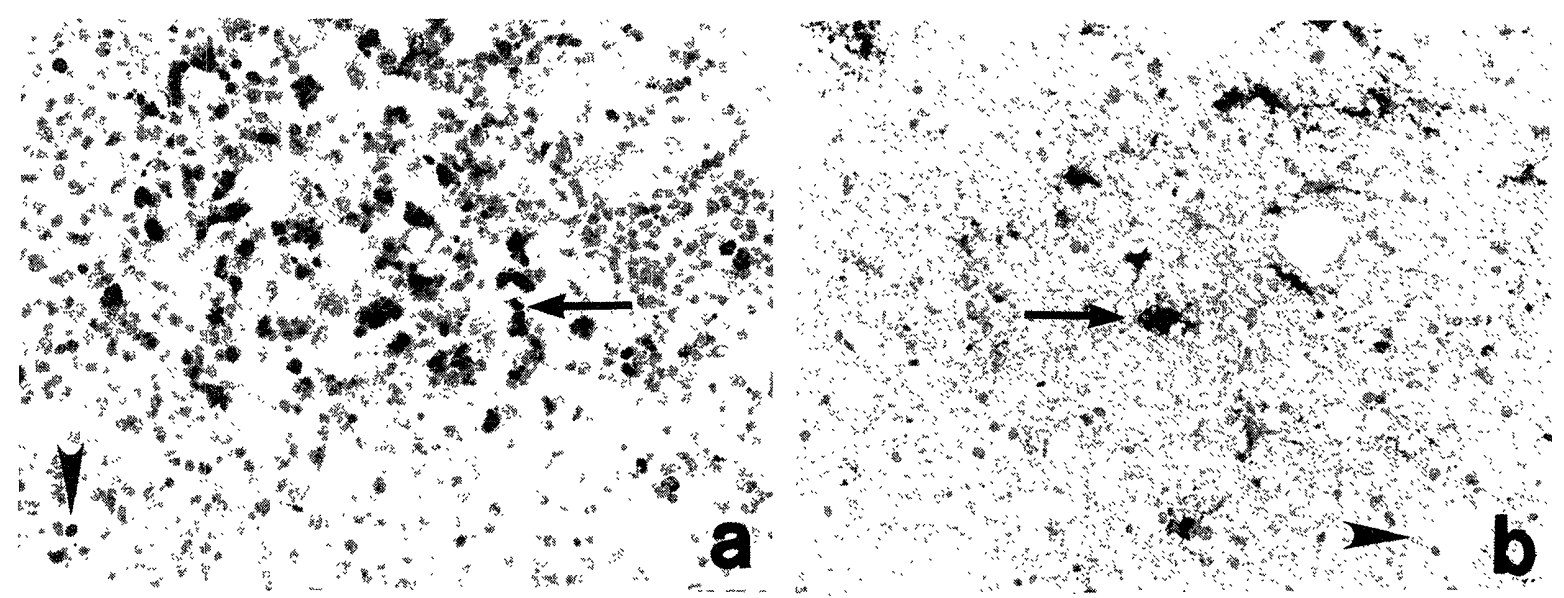

Fig. 1. Virus antigens in the reticular cells (arrow) and lymphocytes (arrowhead) in the lymph node of dog No. 5 (a) and in astrocytes (arrow) in the pons of dog No. 4 (b) stained by ABC method using anti-CDV N protein monoclonal antibody with counter staining by hematoxylin. Demyelination was also observed (b, arrowhead).

Nos. 4 and 5, dog No. 6 was at old age without vaccination record against canine distemper, and was a house dog sent from a different place. From the neurological signs, this dog was speculated to be at late stage of disease. At autopsy, virus neutralizing antibody with a titer of 1:40 was found in the serum but not in the CSF. Thus, virus was successfully isolated in B95a cells from two young dogs and one old dog out of six dogs tested. Virus was consistently isolated from the PBL and brain. In any of the dogs, virus was not isolated from the lung.

Virus isolation in Vero cells was also attempted from the PBL. However, only small foci of cell fusion in Vero cells co-cultured with the PBL of dog No. 5 were noticed at the second passage, and they were failed to be transmitted to the following passages (data not shown). This result was quite similar to the cases of the virus isolation from the human specimens containing low titer of measles virus [8].

Histopathological examinations were conducted on the three dogs from which the virus was isolated. Severe lesions characterized by the depletion of lymphocytes, atrophy of lymphoid follicles and pleuro pneumonia were observed for dog Nos. 4 and 5. Demyelination, vacuolating degeneration and intranuclear inclusion bodies were also observed in the periventricular region in the cerebrum, cerebellum and pons of $\operatorname{dog}$ No. 4. The virus antigens were detected in the lymphocytes and reticular cells in lymph nodes of dog No. 5 as well as in the astrocytes and nerve cells in the brain of dog No. 4 (Fig. 1). In dog No. 6 which showed chronic neurological signs, marked astrocytosis was noticed by GFAP staining, but virus antigen was not detected in these cells. Slightly interstitial pneumonia was also observed.

The viruses isolated from dog Nos. 4 and 5 were considered to be originated from the same outbreak, and the virus of $\operatorname{dog}$ No. 6 from different origin. As shown in Fig. 2, type of CPE in B95a cells was different among the virus isolates. All the viruses of dog Nos. 4 and 5 produced syncytium in B95a cells. For the viruses isolated from dog Nos. 4 and 5, it was also noticed that the viruses from the PBL produced larger syncytium than the ones from the brain. The viruses of dog No. 6 produced round type CPE without syncytium formation. These results indicated that viruses of dog No. 6 had biological characteristics different from those of dog Nos. 4 and 5.

Consequently, a total of eight viruses were isolated in B95a cells from the different tissue samples of three dogs clinically diagnosed as canine distemper. High rate of virus isolation with few passages in the cells indicates a practical usefulness of this cell system for the isolation of CDV circulating in the field similar to the cases of measles virus [12]. B95a cells were found to be much more 

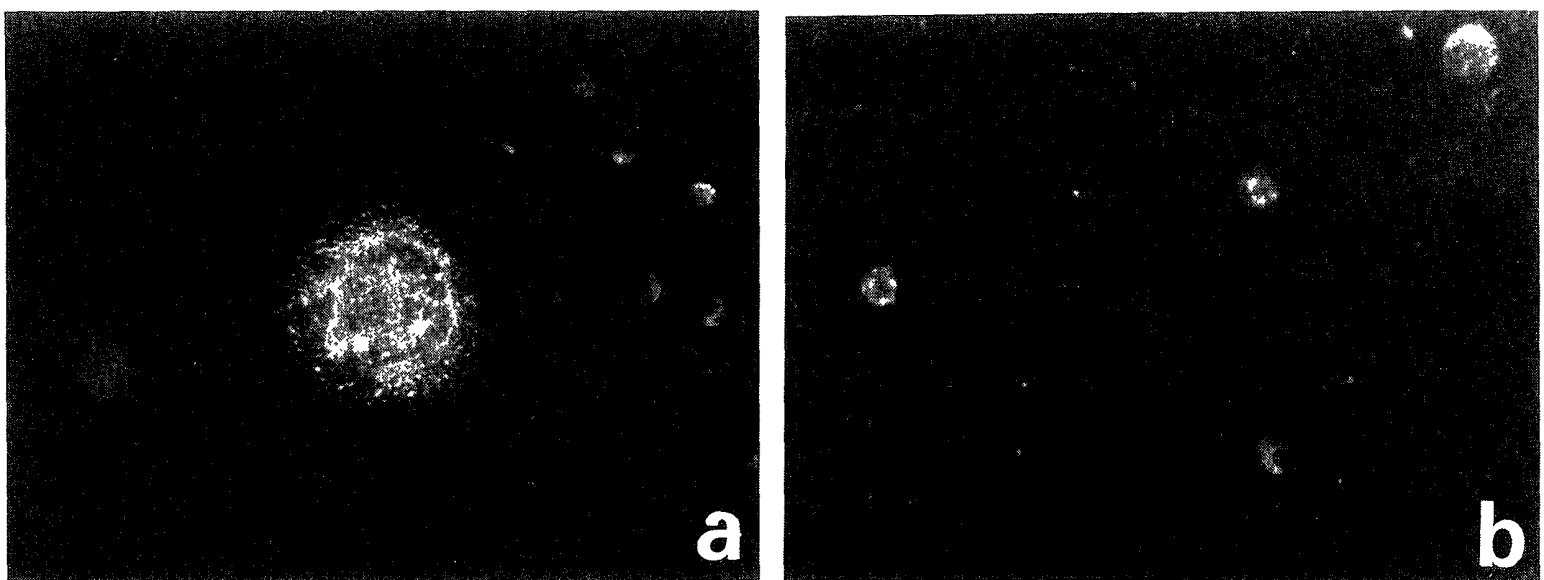

Fig. 2. Syncytium type of CPE in B95a cells produced by the isolated virus from the PBL of dog No. 4 (a) and round-cell type of CPE by the virus from dog No. 6 (b) stained by indirect immunofluorescent technique.

susceptible to CDV than Vero cells which were commonly used for the propagation of CDV. The inferior sensitivity of Vero cells suggests that the growth in Vero cells selects a minor subpopulation of the virus as similarly speculated on the measles virus [8]. The CDV isolates in B95a cells in which CPE was observed quite early were considered to be representative of the viruses circulating in the field. Therefore, this cell system is also indicated to be useful for studying the natural characteristics of the viruses.

Host range of CDV is now considered to be broad. Most terrestrial carnivores which include canidae such as dogs, raccoons and foxes and mustelidae such as minks and badgers are susceptible to CDV. In addition, CDV infection was demonstrated in javelinas [3] and Japanese monkeys [16]. The presence of morbillivirus has been demonstrated in marine mammals such as seals $[10,11$, 15], dolphins [5], and porpoises [7]. Thus ecological studies of CDV is becoming important subject. For this purpose, the virus isolation system using B95a cells is expected to be highly useful.

The isolated viruses in this study are roughly classified into three types, i.e. the virus from the PBL/spleen and that from the brain/CSF from the same outbreak and the virus from the different outbreak. Different types of CPE indicate the presence of different viruses in the field as demonstrated for measles virus isolated in the same cell system [12]. Difference in the size of syncytium formation between the virus from the PBL and that from the brain of the same animal suggests some changes in biological characteristics during replication in different tissues.

The viruses were isolated from two dogs which had received vaccination. Since they were vaccinated at young ages, interference with maternal antibodies is highly probable as a cause of vaccine failure. Possibility of the presence of virus with different antigenicity, however, cannot be exluded. In a preliminary tests using monoclonal antibodies against $\mathrm{H}, \mathrm{F}$, and $\mathrm{N}$ proteins of $\mathrm{CDV}$, two viruses from the brain and PBL of dog No. 6 were found to be different in a particular antigenic epitope of $\mathrm{N}$ proteins compared with the Onderstepoort strain of CDV.
Analysis of antigenic epitopes by monoclonal antibodies as well as comparison of sequences of structural protein genes of the newly isolated viruses are in progress.

ACKNOWLEDGEMENTS. The authors wish to acknowledge Dr. Watari, T., Department of Veterinary Internal Medicine, The University of Tokyo for Providing the clinical history and samples of a diseased dog. This work was supported in part by a Grant-in Aid from the Ministry of Education, Science and Culture, Japan.

REFERENCES

1. Appel, M. J. G. 1987. pp. 133-159. In: Viruses Infections of Carnivores (Appel, M. J. G. ed.), Elsevier Sci. Publ., Amsterdam.

2. Appel, M. J. G. and Jones, O. R. 1967. Proc. Soc. Exp. Biol. Med. 126: 571-574.

3. Appel, M. J. G., Reggiardo, C., Summers, B. A., Pearce-Kelling, S., Mare, C. J., Noon, T. H., Reed, R. E., Shively, J. N., and Orvell, C. 1991. Arch. Virol. 119: 147-152.

4. Center for Disease Control. 1989. United States, first 26 weeks. Morbid. Mortal, Wkly Rep. 38: 863-873.

5. Domingo, M., Ferrer, L., Pumarola, M., Marco, A., Plana, J., Kennedy, S., McAliskey, M., and Rima, B. K. 1990. Nature (Lond.) 384: 21.

6. Hirayama, N., Senda, M., Nakashima, N., Takagi, M., Sugiyama, M., Yoshikawa, Y., and Yamanouchi, K. 1991. J. Gen. Virol. 72: 2827-2830.

7. Kennedy, S., Smyth, J. A., Cush, P. F., Duigna, P., Platten, M., McCullough, S. J., Allan, G. M., and McQauaid, S. 1988. Nature (Lond.) 336: 21.

8. Kobune, F., Sakata, H., and Sugiura, A. 1990. J. Virol. 64: 700-705.

9. Kobune, F., Sakata, H., Sugiyama, M., and Sugiura, A. 1991. J. Gen. Virol. 72: 687-692.

10. Osterhaus, A. D. M. E., Groen, J., de Vries, P., UytdeHaag, F. G. C. M., Klingeborn, B., and Zarnke, R. 1988. Nature (Lond.) 335: 403-404.

11. Osterhaus., A. D. M. E., Groen, J., UytedeHaag, F. G. C. M., Visser, I. K. G., van de Bildt, M. W. G., Bergman, A., and Klingeborn, B. 1989. Nature (Lond.) 338: 209-210.

12. Sakata, H., Kobune, F., Sato, T. A., Tanabayashi, K., 
Yamada, A., and Sugiura, A. 1993. Microbiol. Immunol. 37: 233-237.

13. Shishido, A., Yamanouchi, K., Hikita, M., Sato, T., Fukuda, A., and Kobune, F. 1967. Arch. Ges. Virusforsch. 22: $364-380$.

14. Taylor, M. J., Godfrey, E., Baczko, K., ter Meulen, V., Wild, T. F., and Rima, B. K. 1991. J. Gen. Virol. 72: 83-88.

15. Visser, I. K. G., Kumarev, V. P., Orvel, C., de Vries, P.,
Broeeders, W. J., van de Bildt, M. W. G., Goren J., Teppema, J. S., Burger M. C., UytdeHaag, F. G. C. M., and Osterhaus, A. D. M. E. 1990. Arch. Virol. 111: 149-164.

16. Yoshikawa, Y., Ochikubo, F., Matsubara, Y., Tsuruoka, H., Ishii, M., Shirota, K., Nomura, Y., Sugiyama, M., and Yamanouchi, K. 1989. Vet. Microbiol. 20: 193-205. 